\title{
The obscure events contributing to the evolution of an incipient sex chromosome in Populus: a retrospective working hypothesis
}

\author{
Gerald A. Tuskan • Steve DiFazio • \\ Patricia Faivre-Rampant • Muriel Gaudet • \\ Antoine Harfouche • Véronique Jorge • Jessy L. Labbé • \\ Priya Ranjan • Maurizio Sabatti • Gancho Slavov • \\ Nathaniel Street • Timothy J. Tschaplinski • \\ Tongming Yin
}

Received: 10 May 2011 / Accepted: 8 February 2012 / Published online: 28 March 2012

(C) The Author(s) 2012. This article is published with open access at Springerlink.com

\begin{abstract}
Genetic determination of gender is a fundamental developmental and evolutionary process in plants. Although it appears that dioecy in Populus is genetically controlled, the precise gender-determining systems remain unclear. The recently released second draft assembly and annotated gene set of the Populus genome provided an opportunity to revisit this topic. We hypothesized that over evolutionary time, selective pressure has reformed the genome structure and
\end{abstract}

Communicated by A. Abbott

A contribution to the Special Issue "The genomes of the giants: a walk through the forest of tree genomes"

G. A. Tuskan $(\varangle) \cdot J$. L. Labbé • P. Ranjan · T. J. Tschaplinski BioSciences Division, Oak Ridge National Laboratory,

Oak Ridge, TN 37831, USA

e-mail: gtk@ornl.gov

J. L. Labbé

e-mail: labbejj@ornl.gov

P. Ranjan

e-mail: ranjanp@ornl.gov

T. J. Tschaplinski

e-mail: t2t@ornl.gov

S. DiFazio

Department of Biology, West Virginia University,

53 Campus Drive,

Morgantown, WV 26506-6057, USA

e-mail: stephen.difazio@mail.wvu.edu

P. Faivre-Rampant

UMR1165 INRA, Unité de Recherches en Genomique Vegetale,

2 rue Gaston Cremieux, CP 5708,

91057 Evry, France

e-mail: faivre@evry.inra.fr gene composition in the peritelomeric region of the chromosome XIX, which has resulted in a distinctive genome structure and cluster of genes contributing to gender determination in Populus trichocarpa. Multiple lines of evidence support this working hypothesis. First, the peritelomeric region of the chromosome XIX contains significantly fewer single nucleotide polymorphisms than the rest of Populus genome and has a distinct evolutionary history. Second, the

M. Gaudet $\cdot$ A. Harfouche $\cdot$ M. Sabatti

Department for Innovation in Biological,

Agro-food and Forest Systems, University of Tuscia,

Via S. Camillo de Lellis,

Viterbo 01100, Italy

M. Gaudet

e-mail: gaudet@unitus.it

A. Harfouche

e-mail: aharfouche@unitus.it

M. Sabatti

e-mail: sabatti@unitus.it

V. Jorge

UR0588 INRA, Amélioration, Génétique et Physiologie

Forestières,

2163 avenue de la Pomme de Pin, 40001 Ardon,

45075 Orléans Cédex 2, France

e-mail: veronique.jorge@orleans.inra.fr 
peritelomeric end of chromosome XIX contains the largest cluster of the nucleotide-binding site-leucine-rich repeat (NBS-LRR) class of disease resistance genes in the entire Populus genome. Third, there is a high occurrence of small microRNAs on chromosome XIX, which is coincident to the region containing the putative gender-determining locus and the major cluster of NBS-LRR genes. Further, by analyzing the metabolomic profiles of floral bud in male and female Populus trees using a gas chromatography-mass spectrometry, we found that there are gender-specific accumulations of phenolic glycosides. Taken together, these findings led to the hypothesis that resistance to and regulation of a floral pathogen and gender determination coevolved, and that these events triggered the emergence of a nascent sex chromosome. Further studies of chromosome XIX will provide new insights into the genetic control of gender determination in Populus.

Keywords Gender determination $\cdot$ Sex chromosome $\cdot$ Single nucleotide polymorphisms (SNP) $\cdot$ MicroRNA (miRNA) . Nucleotide-binding site-leucine-rich repeat (NBS-LRR) . Populus

\section{Introduction and background}

Genome structure and synteny map across species

Genus Populus contains approximately 30 species that occur throughout the northern hemisphere and consists of six subgenera or sections: Abaso, Leuce (aka Populus), Leucoides, Aigeiros, Turanga, and Tacamahaca (Eckenwalder 1996). The first investigation of the Populus genome was made in 1921, in which the haploid chromosome number was erroneously reported as four (Graf 1921). By 1924, it became clear that the base chromosome number in Populus was 19 (Harrison 1924). Since then, examination by various scientists has

\footnotetext{
G. Slavov

Institute of Biological, Environmental and Rural Sciences,

Aberystwyth University,

Gogerddan,

Aberystwyth SY23 3EB, UK

e-mail: gts@aber.ac.uk

N. Street

Plant Physiology, Umeå University,

Umea 901 87, Sweden

e-mail: nathaniel.street@plantphys.umu.se

T. Yin

The Key Lab of Forest Genetics and Biotechnology,

Nanjing Forestry University,

159\#, Longpan Road,

210037, Nanjing, China

e-mail: tmyin@njfu.com.cn
}

revealed that all Populus species generally appear as diploids with $2 n=38$ (Smith 1943), with occasional cases of triploid or tetraploid genets arising naturally in various species though more often reported in members of the Leuce subgenera and in interspecific crosses (Einspahr et al. 1963; Bradshaw et al. 2000). Analysis of the assembled genome revealed that the chromosomal structure in modern Populus arose from an ancient whole-genome duplication event known as "salicoid" duplication (Fig. 1) in a progenitor that possessed 12 ancestral chromosomes (Salse et al. 2009). Genome organization and chromosome structure have been conserved among Populus and Salix species (Berlin et al. 2010), and comparisons among Populus and Salix orthologous genes suggest that both genera share this whole-genome duplication event that predated the speciation event (Tuskan et al. 2006). Comparative mapping reveals near-complete marker colinearity in pedigrees established from multiple species within Populus and among members of Salix (Cervera et al. 2001; Hanley et al. 2006; Yin et al. 2004a, 2008; Berlin et al. 2010) (Table 1). Interestingly, Berlin et al. (2010) identified a large region of segregation distortion on linkage group XIX that corresponds to a similar region in chromosome XIX in Populus (Yin et al. 2008).

Members of the genus Populus generally display separate genders on individual trees, i.e., Populus which is dioecious (Slavov et al. 2010; Hughes et al. 2000; McLetchie et al. 1994; Nagaraj 1952), as is Salix (Karp et al. 2011). Only about $4 \%$ of higher plants are dioecious (Ainsworth 2000; Ming et al. 2007; Heslop-Harrison and Schwarzacher 2011). This reproductive habit in Populus, along with the ubiquitous vegetative reproduction via root suckering, air layering, and/or cladoptosis, evolved proximally to or simultaneously with the advent of this family 65 million years ago, as nearly all members of the Salicaceae family displays these habits (Karrenberg et al. 2002; Eckenwalder 1996). Dioecy in Populus is strongly genetically controlled, and a region of the genome located on chromosome XIX appears to contain a gene (genes) that controls gender determination, though there are noted examples of gender reversion and hermaphroditic plants in most species (Rottenberg et al. 2000; Markussen et al. 2007; Yin et al. 2008; Gaudet et al. 2008; Pakull et al. 2009, 2011; Paolucci et al. 2010). The peritelomeric region on chromosome XIX in female Populus trichocarpa genotypes contains approximately $1 \mathrm{Mb}$ of DNA that is not found in male genotypes and appears to have a region of suppressed and/or reduced recombination that extends $3-4 \mathrm{Mb}$ beyond the hemizygous segment in females (Yin et al. 2004a).

These observations suggest that in $P$. trichocarpa, gender is determined using a ZW system where the female genotype is the heterogametic gender (Yin et al. 2008). However, work by Pakull et al. (2011) suggested that both ZZ/ZW (female heterogamety) and XX/XY (male heterogamety) genderdetermining systems could be present in some members of the genus Populus. Gender-determining systems in plants, in 


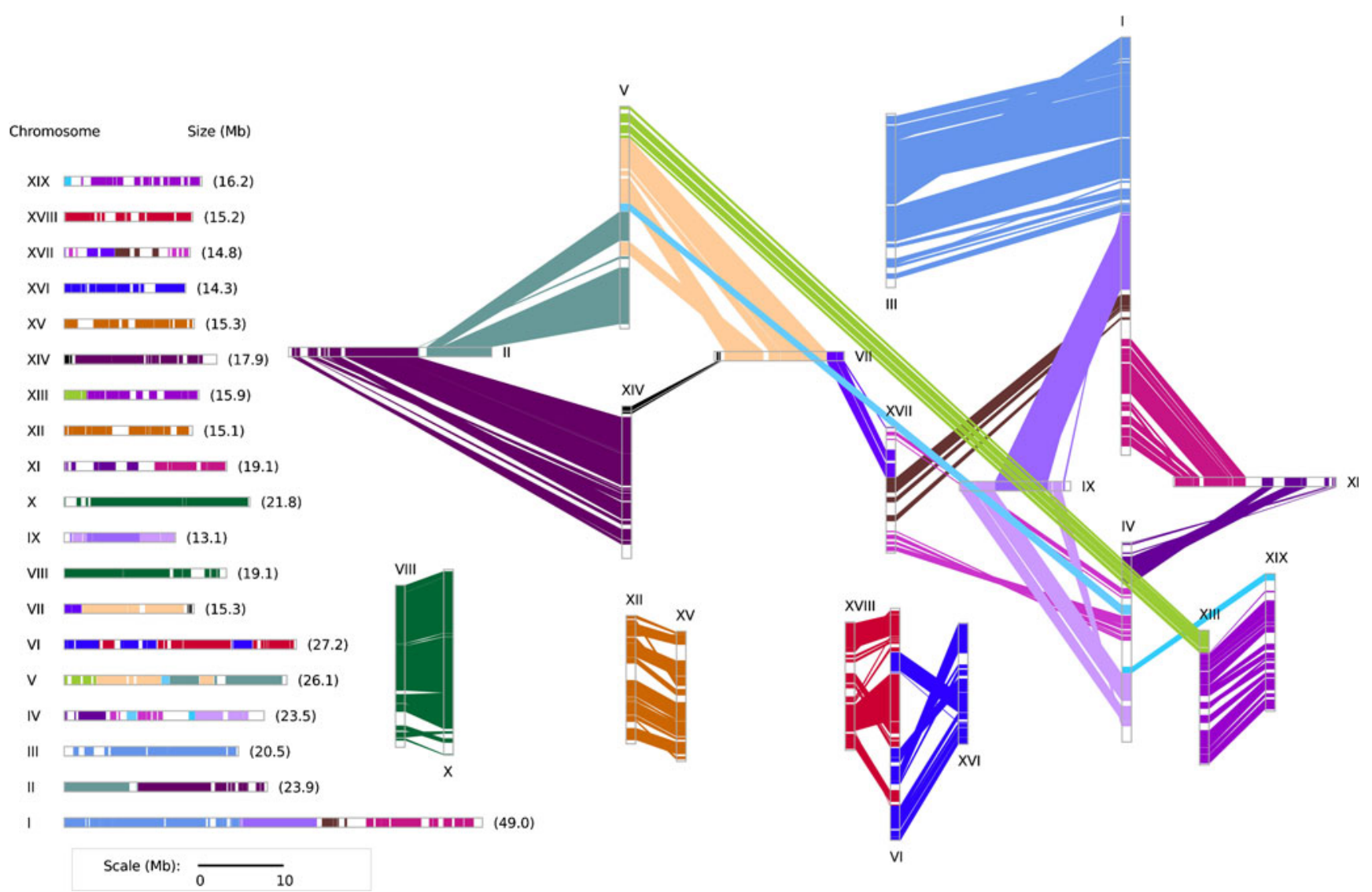

Fig. 1 The "salicoid" duplication event revealed by the Populus genome assembly version 2.2. Common colors refer to homologous genomic blocks. Chromosomes are identified by their linkage group number $(I$ to $X I X)$. The diagram to the left uses the same color-coding

general, exhibit a wide range of diversity to the extreme where some taxa have evolved systems that are unique to those taxa, e.g., in dioecious Rumex species, two different sex and further illustrates the chimeric nature and origin of most chromosomes. Chromosome XIX contains high homology with chromosome XIII expected for the peritelomeric end of XIX which contains the segment related to gender determination

chromosomal systems and sex-determining systems have been described as: (1) $\mathrm{XX} / \mathrm{XY}$ with an active $\mathrm{Y}$ chromosome (e.g., Rumex acetosella) and (2) XX/XY1Y2 with sex

Table 1 Sex ratios in Populus species and hybrids

\begin{tabular}{|c|c|c|c|c|c|c|c|}
\hline \multirow[t]{2}{*}{ References } & \multirow[t]{2}{*}{ Species/hybrid ${ }^{\mathrm{a}}$} & \multicolumn{2}{|c|}{ No. of trees } & \multicolumn{2}{|l|}{ Sex } & \multicolumn{2}{|c|}{ Segregation } \\
\hline & & Total & $\begin{array}{l}\text { Flowering } \\
(\%)\end{array}$ & $\begin{array}{l}\text { No. of } \\
\text { males }(\%)\end{array}$ & $\begin{array}{l}\text { No. of } \\
\text { females }(\%)\end{array}$ & $\mathrm{M} / \mathrm{F}$ ratio & $\chi^{2}$ Ratio \\
\hline Yin et al. (2008) & Populus $x$ canadensis & 312 & $312(100)$ & $197(63.1)$ & $115(36.9)$ & $2: 1$ & $21.5 * * * *$ \\
\hline Paolucci et al. (2010) & P. alba & 154 & $136(88.3)$ & $87(64)$ & $49(36)$ & $2: 1$ & $10.6^{* *}$ \\
\hline Pakull et al. (2011) & Populus $x$ wettsteinii & 130 & $126(96.9)$ & $79(62.7)$ & $47(37.3)$ & $2: 1$ & $8.1^{* *}$ \\
\hline Sabatti et al., unpublished data & P. alba & 251 & $72(28.7)$ & $48(66.7)$ & $24(32.3)$ & $2: 1$ & $8.0 * *$ \\
\hline Vanden Broeck, personal communication & Populus $x$ generosa & 140 & $70(50)$ & $49(70)$ & $21(33.9)$ & $2: 1$ & $11.2 * * *$ \\
\hline Vanden Broeck, personal communication & P. $x$ generosa & 137 & $62(45.2)$ & $41(66.1)$ & $21(33.9)$ & $2: 1$ & $6.45^{*}$ \\
\hline Gaudet et al. (2008) & P. nigra & 165 & $118(71.5)$ & $63(53.4)$ & $55(46.6)$ & $1: 1$ & $0.5 * * * * *$ \\
\hline Vanden Broeck, personal communication & P. $x$ canadensis & 141 & $53(37.6)$ & $21(39.6)$ & $32(60.4)$ & $1: 1$ & $2.3 * * * * *$ \\
\hline
\end{tabular}

Numbers of flowering trees with male and female flowers are presented

${ }^{*} p \leq 0.05 ; * * p \leq 0.01 ; * * * p \leq 0.001 ; * * * * \leq \leq 0.0001$; values are significant at their respective levels; $* * * * p>0.5$; values are nonsignificant at this level

${ }^{a}$ Populus $x$ canadensis, $P$. deltoides $\times$ P. nigra; $P . x$ generosa, $P$. deltoides $\times$ P. trichocarpa; $P . x$ wettsteinii, $P$. tremula $\times$ P. tremuloides 
determination based on the X/A (autosome) ratio (e.g., Rumex acetosa) (Navajas-Pérez et al. 2005). There is also a species, Rumex hastatulus, which has two chromosomal races: the Texas race with $\mathrm{XX} / \mathrm{XY}$ and the North Carolina race with $\mathrm{XX} / \mathrm{XY} 1 \mathrm{Y} 2$. In this species, the $\mathrm{X} / \mathrm{A}$ ratio regulates sex determination, although the presence of the $\mathrm{Y}$ chromosome is necessary for male fertility (Smith 1963).

The chromosomes of Populus are typically metacentric and small (Blackburn and Harrison 1924; Meurman 1925; Erlanson and Hermann 1927; Nakajima 1937; Islam-Faridi et al. 2009), and based on cytological studies, there is no evidence of morphologically differentiated sex chromosomes in any Populus species (Peto 1938; Van Dillewijn 1940; van Buijtenen and Einspahr 1959). One generalized hypothesis is that sex chromosomes originate from autosomes, and dioecy almost certainly evolves from ancestral hermaphrodites that lacked sex chromosomes (Muller 1914;
Liu et al. 2004). Based on genetic mapping results, evidence of sex chromosomes has been reported in various species by Gaudet et al. (2008), Yin et al. (2008), Pakull et al. (2009, 2011), and Paolucci et al. (2010). Yin et al. (2008) described genetic and genomic features in the peritelomeric region of chromosome XIX that suggested this region of the Populus genome is in the process of developing characteristics of a sex chromosome. A provocative feature of chromosome XIX is the location of a gender determination locus, which maps to alternate positions on chromosome XIX, depending upon the Populus species (Gaudet et al. 2008; Pakull et al. 2009, 2011; Yin et al. 2008; Paolucci et al. 2010) (Fig. 2), with a peritelomeric localization in members of the Aigeiros and Tacamahaca subgenera and a centromeric localization in Leuce.

Although mapping studies in Populus revealed that there is a single locus that is associated with gender determination,

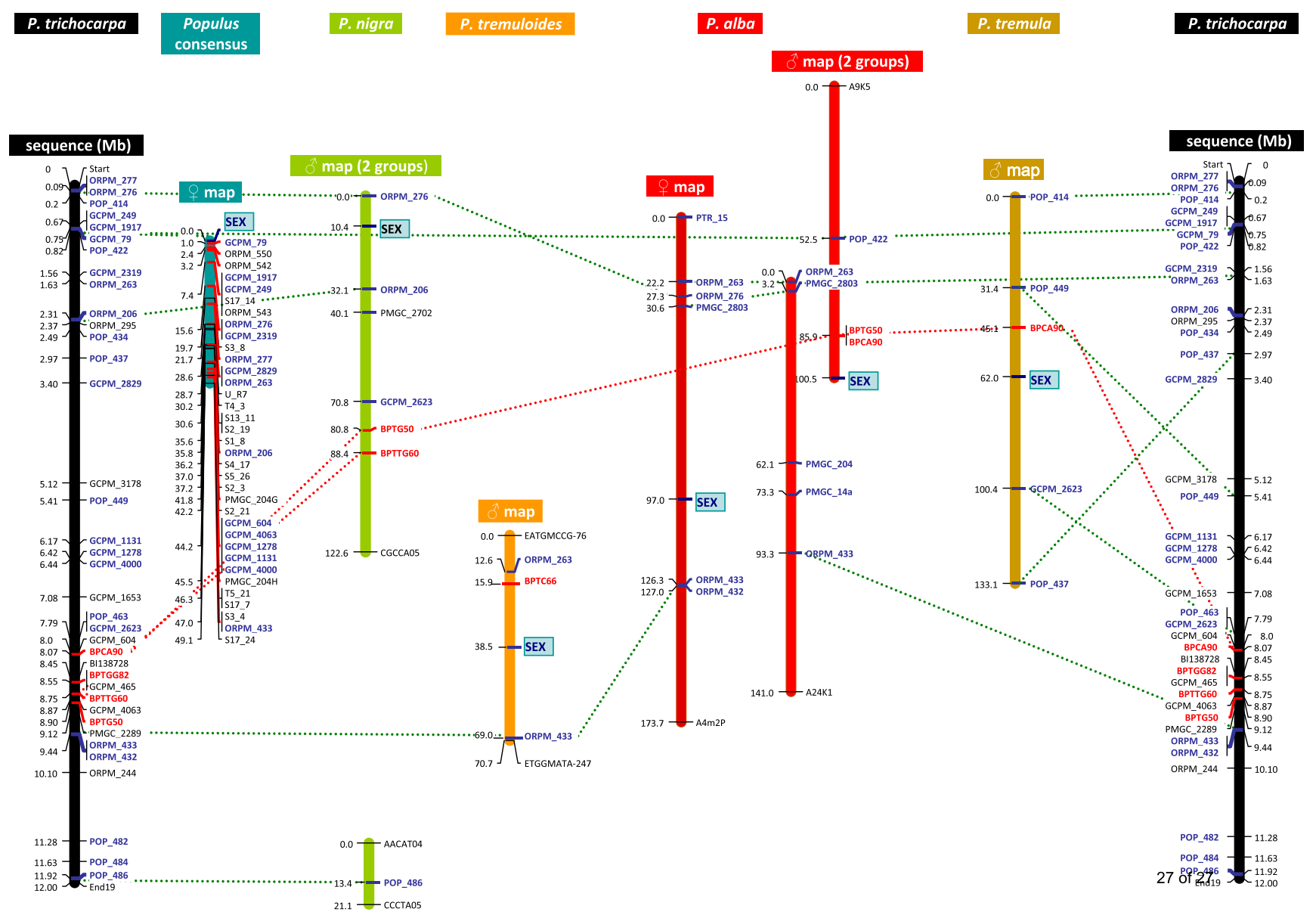

Fig. 2 Comparative mapping of chromosome XIX for gender locus position from different Populus species. Marker positions and distances on P. trichocarpa genome sequence v2.2 are proportional and drawn in black. Lengths of chromosome linkage groups are proportional to map distance in $\mathrm{cM}$. Numbers on the left of each chromosome indicate the marker position. The consensus map (P. trichocarpa and Populus deltoids; Yin et al. 2008) is drawn in blue; the P. nigra map (in green), the Populus tremuloides map (in orange), the Populus alba map (in red) (Gaudet et al., unpublished), and the Populus tremula map (in mustard) (Pakull et al. 2009, 2011). Common SSRs are connected with broken line. SSR in blue were mapped in almost one parent of the pedigrees analyzed. The red SSRs were found linked to gender by Pakull et al. (2011) 
recombination suppression, as noted above, would render all genes within this region as one locus. Thus, the gender locus might encompass several genes underlying gender determination. In support of this supposition, Populus trees show evidence of labile sex expression (Stettler 1971; Rowland et al. 2002). If there is more than one genetic locus determining gender, recombination would impair sexual differentiation. When the recombination suppression is relaxed or translocation of sex determination loci occurs, hermaphrodites may arise (Ming et al. 2007). The observed sex ratios in certain genetic backgrounds of Salix viminalis suggest a multilocus epistatic model of gender determination (Alström-Rapaport et al. 1998). To maintain separate sexes, the genes determining maleness or femaleness would have to be closely linked on opposing haplotypes of a single chromosome, and this region would have to develop local mechanisms to prevent recombination (Ohno 1967; Nei 1969; Charlesworth 1984; Ming et al. 2007).

Multiple lines of evidence from studies focused on $P$. trichocarpa support the role of chromosome XIX in sex determination. First, the sequenced tree, Nisqually-1, is a female, and it showed highly divergent haplotypes in the sex determination region (Tuskan et al. 2006). Second, suppressed recombination in this region was only observed in the female parent. Finally, distorted segregation ratios have been observed in the maternal genotypes of several mapping populations in Populus (Yin et al. 2004a). However, the gender-determining locus has not been resolved into an individual gene (genes) yet. As noted above, in P. trichocarpa and other members of the Aigeiros and Tacamahaca subgenera, the gender locus is located in peritelomeric region of chromosome XIX. However, in members of the Leuce subgenera, the gender-determining locus appears to be located near the centromere (Fig. 2). A segmental inversion on the maternal haplotype of chromosome XIX or a completely unique set of genetic loci in the centromeric region of the Leuce species may account for this difference and may be one of the reasons that members of the Leuce subgenera are generally not sexually compatible with other subgenera in interspecific crosses (Liesebach et al. 2011). Interestingly, in contrast with $P$. trichocarpa, a member of the Tacamahaca subgenera, an XY sex determination system appears to be in place in the Aigeiros and Leuce species.

The Populus genome was sequenced, assembled, annotated, and released in 2006, and at the time, represented the most polymorphic genome to be assembled using wholegenome shotgun approaches (Tuskan et al. 2006). A second draft assembly and annotated gene set was released in 2010 (http://www.phytozome.net/poplar), and the assembled sequence now captures roughly $83 \%$ of the nucleotide (nt) space, and approximately 43,000 predicted gene models have been used to create and inform whole-genome microarray studies (Jansson and Douglas 2007), saturated genetic
maps/QTL studies (Yin et al. 2008), and proteomics reference libraries (Abraham et al. 2011).

From a genome resequencing effort, we discovered that the gender-linked peritelomeric region of the chromosome XIX contains significantly fewer single nucleotide polymorphisms (SNP) than the rest of Populus genome (Fig. 3). There are approximately $1.8 \mathrm{SNPs}$ per $1 \mathrm{~kb}$ of sequence at the peritelomeric end of chromosome XIX versus 2.6 SNP per $1 \mathrm{~kb}$ on the average across the entire genome. The peritelomeric end of chromosome XIX also appears to have a distinct evolutionary history compared to the rest of the genome as demonstrated by its alignment to the Vitis genome (Jaillon et al. 2007, Fig. 2a), where the peritelomeric end of chromosome XIX distinctively lacks homology with genomic segments found in the Vitis genome. The peritelomeric end of chromosome XIX also lacks homology with any of the duplicated segments associated with salicoid duplication (Fig. 1).

In addition, the peritelomeric end of chromosome XIX contains the largest cluster of the nucleotide-binding siteleucine-rich repeat (NBS-LRR) class of disease resistance genes in the entire Populus genome (Tuskan et al. 2006; Kohler et al. 2008). NBS-LRR genes function in the detection of pathogen occurrence and convey disease resistance signaling to activate gene expression. There is also a disproportionately high occurrence of small (18-24 nt) microRNAs (miRNA) on chromosome XIX coincident to the region containing the putative gender-determining locus and the major cluster of NBS-LRR genes (Klevebring et al. 2009). Such miRNAs are a class of posttranscriptional negative regulators that play a vital role in plant development and growth (Jones-Rhoades et al. 2006; Shuklaa et al. 2008; Henderson et al. 2006; Chan et al. 2005). A number of the identified miRNA are predicted to target the NBS-LRR disease resistance genes within the peritelomeric region of chromosome XIX. Furthermore, the NBS-LRR genes have been significantly expanded in Populus relative to Arabidopsis (Kohler et al. 2008; Meyers et al. 2003).

\section{The hypothesis}

Based on the above information, the following is a working hypothesis for the evolution of an incipient sex chromosome in Populus. Specifically, prior to the advent of the crown taxa of the family Salicaceae, there was a common progenitor of all modern Salicaceae species that was monecious, diploid, capable of vegetative reproduction via adventitious root formation, and susceptible to pathogenic attack isolated to its stigma and/or style. The pathogen caused complete necrosis of all female reproductive structures such that sexual reproduction was disrupted, favoring genes that facilitated the establishment and promulgation of vegetative 


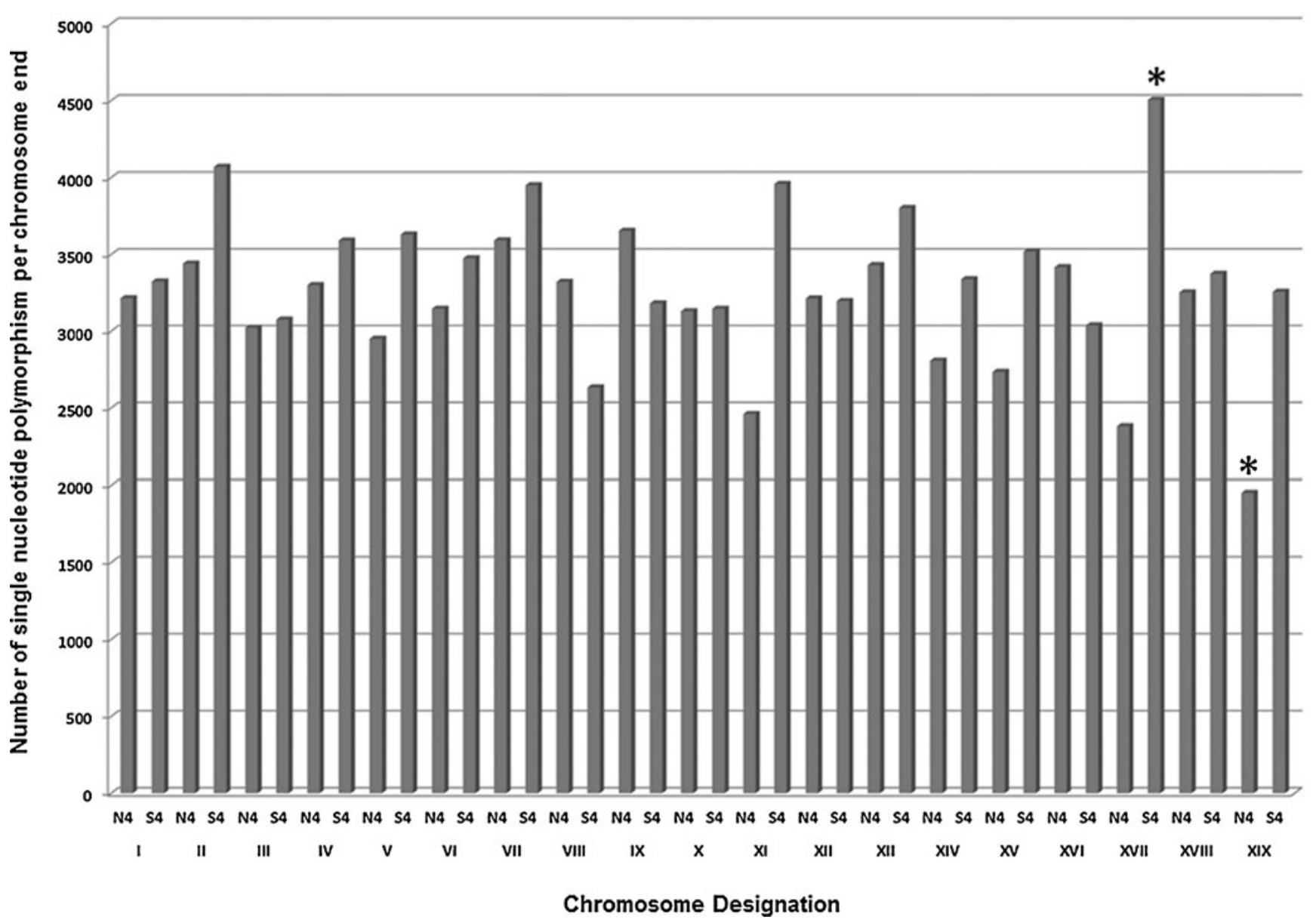

Fig. 3 Single nucleotide distribution across all 19 Populus chromosomes, with $N$ and $S$ representing an arbitrary $4 \mathrm{Mb}$ "north" and "south" end of each chromosome. The S4 and N4 regions of

propagation. Extended interannual vegetative propagation allowed time for somatic mutations to occur, experience selection pressure, and accumulate favorable alleles in the susceptible progenitor genotype. Favorable mutations at multiple independent loci then formed the basis of resistance to the putative female-specific floral pathogen. Selective pressure from the putative pathogen also facilitated the accumulation of miRNA targets within transcripts of the genes responsible for this resistance as a means of regulating gene expression. Over evolutionary time, small translocations within the progenitor genome disproportionately resulted in the accumulation of resistance genes on the peritelomeric portion of chromosome XIX, which then minimized linkage disequilibrium between the individual resistance loci required for female organ function and survival. Suppressed recombination associated with the telomere reduced the genetic load on the progeny and allowed these genes to be inherited as a haplotypic block. Translocation of genes related to female organogenesis to the peritelomeric end of chromosome XIX ultimately resulted in dioecy. All modern taxa in the family Salicaceae, descendants of this chromosomes XVII and XIX contain significantly $(p \leq 0.01)$ more and fewer SNP than expected by chance alone, respectively

progenitor, are now dioecious, capable of vegetative propagation, and have syntenic chromosome structure. Selective sweep associated with these events is evident in the reduced number of single nucleotide polymorphisms in the peritelomeric region of chromosome XIX.

\section{Evidence in the modern Populus genome}

The lack of comparative synteny on chromosome XIX with Vitis, the suppressed recombination in the peritelomeric end of chromosome XIX, and the reduced number of SNP found in this region are consistent with the occurrence of a selective sweep in Populus. Reduction in the accumulation of genetic mutations is a classic indication of an ancient severe genetic bottleneck within the evolution history of an organism or segment of DNA. Paape et al. (2008) reported a similar event in Solanaceae where the founding members of the extant genera Physalis and Witheringia appear to have been derived from a reduced number of lineages in genomic regions surrounding the S-locus for self-incompatibility. The 
fingerprints of restricted founding lineages and genetic bottleneck are also present in many modern domesticated crop plants where artificial selection has reduced the amount of genetic variation surrounding loci associated with domestication (Purugganan and Fuller 2009; Hyten et al. 2006; Palaisa et al. 2004). Based on nucleotide diversity, the peritelomeric end of chromosome XIX appears to be younger than the rest of the Populus genome. Interestingly, similar observations have been made for the $\mathrm{X}$ chromosomes in humans and mice (Hughes et al. 2010; Patterson et al. 2006).

Floral pathogens and floral biochemistry

Many species of plants have evolved methods of producing antibacterial and antifungal compounds in their floral tissues (Tavares et al. 2008; Jones and Dangl 2006; Lokvam and Braddock 1999; Carlson et al. 1948). These compounds are thought to protect the flowers from lethal and semilethal attacks from microorganisms (Theis et al. 2009; Thadeo et al. 2008; Vamosi and Otto 2002). Moreover, many of these compounds vary between tissue types, flower structures, gynomorphs, and andromorphs (Kaltz and Shykoff 2001; Strauss 1997; Carlson et al. 1948). In addition, there are several plant diseases that are known to affect only the male or female structures of perfect flowers or male or female flowers in dioecious plant species (Giles et al. 2006; Lokvam and Braddock 1999). Finally, there are plant pathogens that gain access via the stigma or style tissue within female flowers (Pusey and Curry 2004; Stretch and Ehlenfeldt 2000; Shykoff et al. 1997).

Populus and other members of the Salicaceae family are known to produce antimicrobial and antifungal compounds in nectary found near meristematic tissues, and that these compounds contribute to plant adaptive success (Heil 2008; Thadeo et al. 2008). A gas chromatography-mass spectrometry (GC-MS) analysis of the metabolomic profiles of expanding floral buds of 16 trees (12 females and 4 males) from two Populus species (Populus deltoides and Populus nigra) was conducted to determine whether secondary metabolites were correlated with gender (Table 2). Species differences in secondary metabolites of Populus are well documented (Greenaway and Whatley 1990, 1991a, b; Greenaway et al. 1989, 1992; Tsai et al. 2006), and male and female flowers of Salix display gender-specific floral scent characteristics (Fussel et al. 2007). Our analyses demonstrate metabolite differences between genders, that is, although buds of both species and both genders contain pinobanskin-3-acetate, pinobanksin-3-acetate chalcone and pinobanksin and 3isobutanoate, the male floral buds contained very low concentrations of these metabolites. In contrast, P. nigra males contained high concentrations of higher-order populin conjugates, including 6-hydrocyclohexenyl ( $\mathrm{HCH})$-populin and populin conjugated with benzoic acid and another unknown 476 Da moiety. Moreover, several secondary metabolites were orthogonally associated with gender. This included major secondary metabolites of Populus, including salicortin and salireposide, which were higher in females. There were also several unidentified secondary metabolites that were much higher in female buds, including a metabolite tentatively identified as caffeoyl-populoside and a series of metabolites that all share a $171 \mathrm{~m} / \mathrm{z}$ moiety, along with a coumarate glycoside conjugate (retention time (RT) $18.78 \mathrm{~min}$ ) and a caffeoyl glycoside conjugate (RT $19.3 \mathrm{~min}$ ). Scanning for the unidentified $171 \mathrm{~m} / \mathrm{z}$ moiety resulted in the identification of several additional secondary metabolites uniquely associated with female floral buds, including a feruloyl glycoside conjugate (RT $19.36 \mathrm{~min}$ ) and a benzyl-caffeoyl glycoside conjugate (RT $20.3 \mathrm{~min}$ ). Taken together, these preliminary analyses suggest that there are gender-specific accumulations of phenolic glycosides. Based on these results, antimicrobial and antifungal compounds appear to be differentially found in male and female floral structures.

\section{LRR genes}

As a perennial organism, Populus species interact with numerous diverse microorganisms over periods of decades (Gottel et al. 2011). In order to survive, Populus species must resist against recurring, perpetual pathogenic attack. Moreover, with a large root system maintaining water and

Table 2 Concentrations (ug/g FW sorbitol equivalents) of Populus floral bud metabolites associated with gender

\begin{tabular}{|c|c|c|c|c|c|c|c|c|}
\hline Species & Gender & Salicortin & Salireposide & $\begin{array}{l}18.78-171 \\
331 \text { Coumaroyl } \\
\text { glycoside }\end{array}$ & $\begin{array}{l}19.30-171 \\
331 \text { Caffeoyl } \\
\text { glycoside }\end{array}$ & $\begin{array}{l}\text { 19.36-171 } \\
\text { Feruloyl } \\
\text { glycoside }\end{array}$ & $\begin{array}{l}20.30-171 \\
\text { Benzyl-caffeoyl } \\
\text { glycoside }\end{array}$ & $\begin{array}{l}22.06 \\
\text { Caffeoyl- } \\
\text { populoside }\end{array}$ \\
\hline P. nigra & Female & $2,110.5(210.8)$ & $116.3(16.1)$ & $43.1(4.7)$ & $11.8(3.3)$ & $41.8(4.4)$ & $17.1(3.5)$ & $28.3(11.7)$ \\
\hline P. deltoides & Female & 1,991.7 (145.6) & $100.9(13.9)$ & $31.6(4.2)$ & $13.8(1.6)$ & $37.5(6.0)$ & $10.7(3.8)$ & $32.3(6.7)$ \\
\hline P. nigra & Male & $488.3(143.2)$ & $13.9(3.8)$ & $1.9(0.3)$ & $0.3(0.2)$ & $0(0)$ & $0(0)$ & $0.2(0.2)$ \\
\hline P. deltoides & Male & $1,243.0(97.4)$ & $45.7(4.5)$ & $9.2(8.2)$ & $5.1(0.6)$ & $20.6(0.7)$ & $0(0)$ & $9.7(3.1)$ \\
\hline
\end{tabular}

As determined by gas chromatography-mass spectrometry; retention time and key m/z are shown at the column headings; mean and SEM () of two male to six female replicate buds are shown within rows 
nutrient uptake and functioning to facilitate interannual store of carbon over multiple decades, the selective pressure to develop symbiotic interactions with soil microflora may be as strong as to develop pathogenic resistances. As an illustration, various loci controlling variation for both symbiosis levels and resistance have been identified in Populus (Zhang et al. 2001; Yin et al. 2004b; Jorge et al. 2005; Tagu et al. 2005; Kohler et al. 2008; Duplessis et al. 2009; Labbé et al. 2011).

Plants, in general, and Populus, in particular, have a variety of disease resistance genes $(R)$ encoding proteins involved in the detection of pathogens and herbivores. The largest class of R-genes encodes intracellular nucleotidebinding site-leucine-rich repeat proteins, and they are divided into two main subfamilies (TNL and TIR) based on their predicted N-terminal protein domains (McDowell and Wolffenden 2003). NBS-LRR genes are known to trigger protease inhibitor activity; control protease, chitinase, and kinase production; and regulate salicylic acid, jasmonic acid, ethylene, and nitric oxide signaling (Duplessis et al. 2009; Sánchez-Rodríguez et al. 2009; McHale et al. 2006; Meyers et al. 1999, 2003; McDowell and Wolffenden 2003). In Populus, 37 NBS-LRR genes are found in the peritelomeric region of chromosomes XIX and represents nearly $10 \%$ of all NBS-LRR found throughout the rest of the genome (Tuskan et al. 2006; Kohler et al. 2008, Fig. 1).

Genome-wide, roughly 400 NBS-LRR genes have been identified in Populus, which is approximately double the number identified in Arabidopsis (Kohler et al. 2008). The higher number in Populus appears to represent an expansion in Populus rather than a contraction in Arabidopsis (Meyers et al. 2003; Tuskan et al. 2006; Kohler et al. 2008). Indeed, a remarkable feature of plant NBS-LRR genes is their genomic organization in multigene clusters (Kohler et al. 2008; Yang et al. 2008). In Populus, these clusters are distributed unevenly over the chromosomes and in clusters of clusters or "superclusters" of which three occur on chromosome XIX. Highly similar sequences in head-to-tail orientation suggest that intralocus recombination gave rise to the translocation of a sequence block (Richy et al. 2002). The largest NBS-LRR gene supercluster on Populus chromosome XIX collocates with the resistance loci $M E R, R 1$, and $R U S$, conferring qualitative or quantitative resistance to Melampsora larici-populina (Lescot et al. 2004; Jorge et al. 2005; Bresson et al. 2011). Thus, ancient segmental duplication and subsequent chromosomal rearrangement that accounted for $10 \%$ of the amplification of NBS superclusters suggests positive selective pressure on chromosome XIX that may expedite the progression of sex chromosome evolution.

\section{Short RNAs}

In Populus, there are still only a small number of publications that have examined or profiled miRNAs, and only one that has examined the entire sRNA population (Klevebring et al. 2009). An intriguing finding from the data presented in Klevebring et al. (2009) was that the proposed sexdetermining peritelomeric region of chromosome XIX showed a distinctive pattern of sRNA occurrence that differed significantly from the rest of the genome. Within this region, there was distinct overrepresentation of 21 and $24 \mathrm{nt}$ sRNAs along with a phased siRNA locus. Target prediction of the phased siRNAs indicates that they target NBS-LRR genes within the same region of chromosome XIX.

Using the methodology outlined in Klevebring et al. (2009), but applied to v2.2 of the P. trichocarpa genome assembly (http://www.phytozome.net/poplar), we recharacterized sRNA occurrence. Based on our reanalysis, there was an above average occurrence of sRNAs from the upper $1 \mathrm{Mb}$ of chromosome XIX, in particular, 21 and $24 \mathrm{nt}$ sRNAs (as was reported in Klevebring et al. 2009). Because the reference genome represents a female $P$. trichocarpa genotype, it is not known whether this pattern is present in both males and females, or whether there are sex-specific differences in the sRNA population produced from this region. Such patterns have not been reported in other species.

In contrast to the v1.1 analysis, five phased loci were identified on chromosome XIX with four of the five located within the peritelomeric end of chromosome XIX (e.g., Fig. 4). Target prediction of these four loci identified nearexclusive targeting of NBS-LRR genes with almost all target genes located within the peritelomeric region of chromosome XIX. Deeper sequencing and profiling of additional tissues and developmental states will be needed to clarify these results, as read counts for nearly all sequences within the loci were low $(<5)$; however, it appears that alternate male and female haplotypes may have haplotype-specific phased loci that target NBS-LRR genes in a haplotypespecific manner.

Many miRNA families regulate the development in Arabidopsis and have been shown to be necessary for proper specification of floral organ identity (e.g., miR172; JonesRhoades et al. 2006; Mallory and Vaucheret 2006). Arabidopsis plants that over express miR172 have floral defects that resemble APETALA2-like loss-of-function mutants where there is an absence of petals and sepals and an excess of carpels (Aukerman and Sakai 2003; Chen 2004). Moreover, recent studies investigating genes that control sex determination in maize reveals that a miRNA is involved in the determination of the male inflorescence (Banks 2008). Here, the tasselseed 4 miRNA, i.e., miR172, targets APETALA2 floral homeotic transcription factors (Chuck et al. 2007). miR172 also targets F-box family protein (FKF1) in Arabidopsis, and in Eschscholzia californica, miR172 appears to control protein degradation and sex determination (Barakat et al. 2007b). Interestingly, the miR172 family 


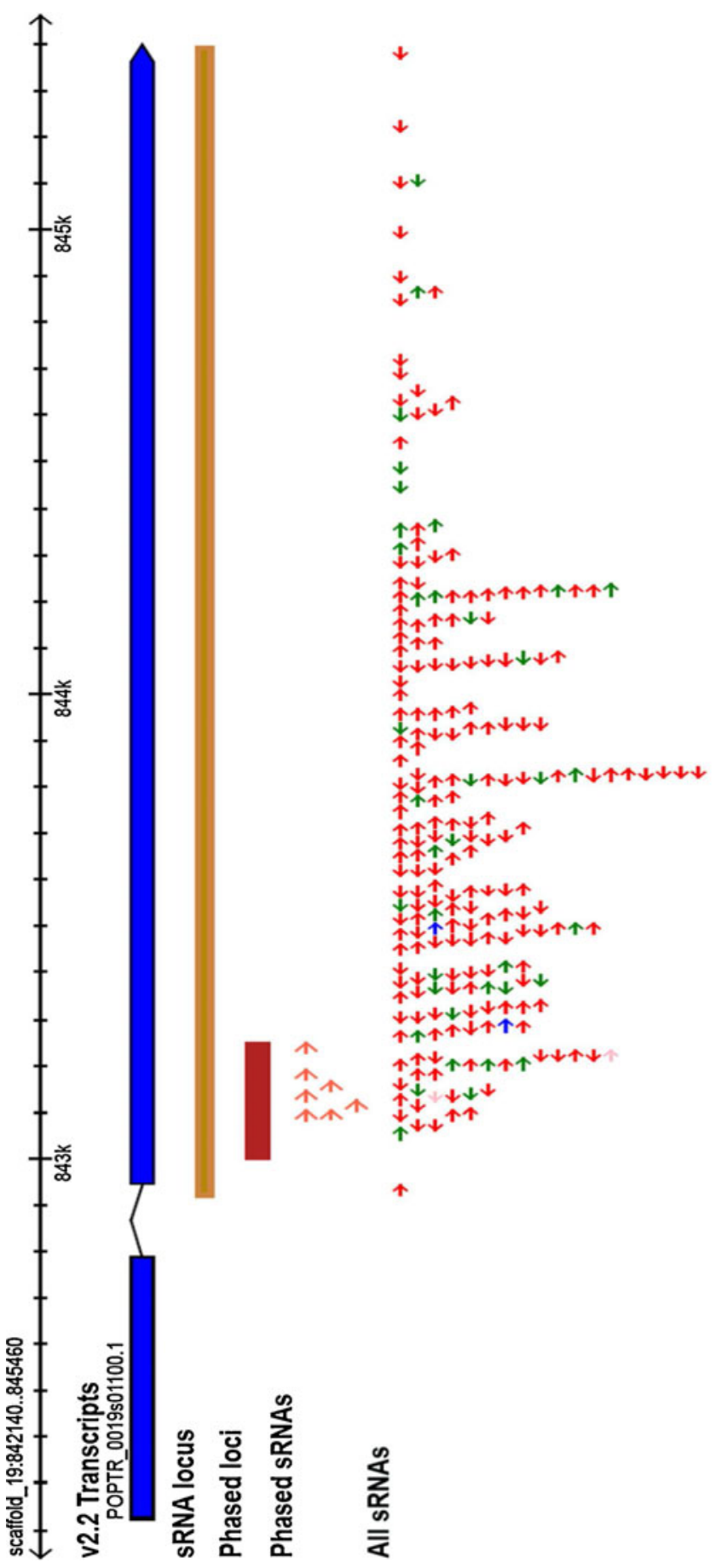

Fig. 4 A phased sRNA locus located on chromosome XIX. The phased locus is located within the second exon of POPTR_0019s01100, a gene containing multiple leucine-rich repeat domains. The sRNA locus and phased locus shown were identified using the UEA plant sRNA toolkit (http://srna-tools.cmp.uea.ac.uk/). Phased sRNA sequences are shown as are all sRNA sequences within the identified sRNA locus. sRNA sequence colors indicate size class: pink $\leq 19 \mathrm{bp}$, red $\leq 21 \mathrm{bp}$, green $\leq 23 \mathrm{bp}$, blue $\leq 25$ bp. All sRNA data are from Klevebring et al. (2009)

is conserved in Populus (Barakat et al. 2007a) and is located on the peritelomeric end chromosome XIX, and coincidentally, there is an under representation of F-box genes in the peritelomeric region of chromosome XIX in Populus (Yang et al. 2008, Fig. 1).

Future characterizations of the role of miRNAs in sex determination in Populus may illuminate biochemical preferences in the sex determination pathway and, in the process, define male/female differentiation. Deep sequencing of miRNAs from pre- and postdifferentiated male and female floral meristems will be necessary to understand which miRNAs change during differentiation and to determine the target gene upon which they act.

The metabolic differences between male and female flowers, the overrepresentation of NBS-LRR genes, the presence of phased sRNA loci targeting those genes, and the generally higher than average production of sRNAs, all which collocate with gender, support the hypothesis that resistance to and regulation of a floral pathogen and gender determination coevolved in a region of the genome that experiences reduced recombination, i.e., the peritelomeric region of chromosome XIX in P. trichocarpa.

\section{Conclusions}

Genetic determination of gender occurs in most plant species and is a fundamental developmental and evolutionary process. The sexual phenotypes of commercially important Populus species and their varieties will dictate how they are bred and cultivated. Understanding of the genetic mechanisms guiding this intricate process is in its infancy. Thus, dissecting the mechanisms underlying gender determination in Populus will allow several evolutionary, developmental, and economic questions to be resolved. Based on various Populus species, we suggest that the gender determination may vary among species, with some species following a $\mathrm{ZW}$ gender determination system and other using a XY system. Identifying the molecular basis of floral differentiation that cosegregate with gender represents a promising approach to define the gender-determining system in Populus. Resequencing and expression studies in parental, $F_{1}$, and $F_{2}$ generations will enable us to definitively identify the heterogametic sex.

While genetic linkage mapping studies have started to reveal regions of recombination suppression in Populus, identifying the actual gene or genes involved in gender determination remains a prime objective. Greater effort in comparative mapping, targeted resequencing, genderspecific expression studies, and physical mapping efforts will be invaluable in discovering the key gene or genes and in answering questions about their evolution. These types of information will shed light on the developmental patterns of gender determination and evolution of sex chromosomes. Finally, cloning the Populus gender-determining genes and complementation transgenic experiments will 
ultimately be needed to unravel the role of genetic and epigenetic factors in gender determination. The genus Populus is an excellent model for studying the evolution of gender determination because of the genus-wide occurrence of dioecy-related gender-determining systems that can provide new perspectives on the genetic mechanism of gender determination in plants in general. With the availability of the whole-genome sequence and the initiation of a number of efforts to characterize adaptive polymorphisms and gender determination in natural and structured populations, answers to these and other intriguing questions about the evolutionary biology of this model genus will emerge in the near future.

Acknowledgments General analysis and writing of this paper were supported by the BioEnergy Science Center, a US Department of Energy Bioenergy Research Facility supported by the Office of Biological and Environmental Research in the DOE Office of Science. Oak Ridge National Laboratory is managed by the University of Tennessee-Battelle LLC for the Department of Energy. AH is supported by the Brain Gain Program (Rientro dei cervelli) of the Italian Ministry of Education, University and Research (MIUR).

Open Access This article is distributed under the terms of the Creative Commons Attribution License which permits any use, distribution, and reproduction in any medium, provided the original author(s) and the source are credited.

\section{References}

Abraham P, Adams R, Giannone RJ, Kalluri U, Ranjan P, Erickson B, Shah M, Tuskan GA, Hettich RL (2011) Defining the boundaries and characterizing the landscape of functional genome expression in vascular tissues of Populus using shotgun proteomics. J Proteome Res. doi:10.1021/pr200851y

Ainsworth C (2000) Boys and girls come out to play: the molecular biology of dioecious plants. Ann Bot 86:211-221

Alström-Rapaport C, Lascoux M, Wang YC, Roberts G, Tuskan GA (1998) Identification of a RAPD marker linked to sex determination in the basket willow (Salix viminalis L.). J Hered 89:44-49

Aukerman MJ, Sakai H (2003) Regulation of flowering time and floral organ identity by a microRNA and its APETALA2-like target genes. Plant Cell 15:2730-2741

Banks J (2008) MicroRNA, sex determination and floral meristem determinacy in maize. Genome Biol 9(1):204

Barakat A, Wall PK, Diloreto S, Depamphilis CW, Carlson JE (2007a) Conservation and divergence of microRNAs in Populus. BMC Genomics 8:481-496

Barakat A, Wall K, Leebens-Mack J, Wang YJ, Carlson JE, DePamphilis CW (2007b) Large-scale identification of microRNAs from a basal eudicot (Eschscholzia californica) and conservation in flowering plants. Plant J 51:991-1003

Berlin S, Lagercrantz U, von Arnold S, Öst T, Rönnberg-Wästljung AC (2010) High-density linkage mapping and evolution of paralogs and orthologs in Salix and Populus. BMC Genomics 11:129143

Blackburn KB, Harrison JWH (1924) A preliminary account of the chromosomes and chromosome behavior in the Salicaceae. Ann Bot 38:361-378
Bradshaw HD, Ceulemans R, Davis J, Stettler R (2000) Emerging model systems in plant biology: poplar (Populus) as a model forest tree. J Plant Growth Regul 3:306-313

Bresson A, Jorge V, Dowkiw A, Guerin V, Bourgait I, Tuskan GA, Schmutz J, Chalhoub B, Bastien C, Faivre-Rampant P (2011) Qualitative and quantitative resistances to leaf rust finely mapped within two nucleotide-binding site leucine-rich repeat (NBSLRR)-rich genomic regions of chromosome 19 in poplar. New Phytol 192:151-163

Carlson HJ, Douglas HG, Robertson J (1948) Antibacterial substances separated from plants. J Bacteriol 55:241-248

Cervera MT, Storme V, Ivens B, Gusmao JH, Liu B, Hostyn V, Slycken JV, Van Montagu M, Boerjan W (2001) Dense genetic linkage maps of three Populus species (P. deltoides, P. nigra and $P$. trichocarpa) based on AFLP and microsatellite markers. Genetics 158:787-809

Chan S, Henderson WL, Jacobsen IR, May SE (2005) Gardening the genome: DNA methylation in Arabidopsis thaliana. Nat Rev Genet 6(5):351-360

Charlesworth D (1984) Androdioecy and the evolution of dioecy. Biol J Linn Soc 23:333-348

Chen X (2004) A microRNA as a translational repressor of APETALA2 in Arabidopsis flower development. Science 303:2022-2025

Chuck G, Meeley R, Irish E, Sakai H, Hake S (2007) The maize tasselseed 4 microRNA controls sex determination and meristem cell fate by targeting tasselseed6/indeterminate spikelet1. Nat Genet 39:1517-1521

Duplessis S, Major I, Martin F, Seguin A (2009) Poplar and pathogen interactions: insights from Populus genome-wide analyses of resistance and defense gene families and gene expression profiling. Crit Rev Plant Sci 28(5):309-334

Eckenwalder JE (1996) Systematics and evolution of Populus. In: Stettler RF, Bradshaw HD Jr, Heilman PE, Hinckley TM (eds) Biology of Populus and its implications for management and conservation. NRC Research Press, Ottawa, pp 7-32

Einspahr D, Benson MK, Peckham JR (1963) Natural variation and heritability in triploid aspen. Silvae Genet 12:51-58

Erlanson EW, Hermann FJ (1927) The morphology and cytology of perfect flowers in Populus tremuloides Michx. Mich Acad Sci Arts Lett 8:97-110

Fussel U, Dotterl S, Jurgens A, Aas G (2007) Inter- and intraspecific variation in floral scent in the genus Salix and its implication for pollination. J Chem Ecol 33:749-765

Gaudet M, Jorge V, Paolucci I, Beritognolo I, Scarascia Mugnozza G, Sabatti M (2008) Genetic linkage maps of Populus nigra L. including AFLPs, SSRs, SNPs and sex trait. Tree Genet Genomes $4(1): 25-36$

Giles B, Pettersson T, Corlsson-Granér U, Ingvarsson P (2006) Natural selection on floral traits of female Silene dioica by a sexually transmitted disease. New Phytol 169:729-739

Gottel NR, Castro HF, Kerley M, Yang Z, Pelletier DA, Podar M, Karpinets T, Uberbacher E, Tuskan GA, Vilgalys R, Doktycz MJ, Schadt CW (2011) Populus deltoides roots harbor distinct microbial communities within the endosphere and rhizosphere across contrasting soil types. App Environ Microbiol 77(17):5934-5944

Graf J (1921) Beitrage zur Kenntnis der Gattung Populus. Berichte der Deutschen Botanischen Gesellschaft 38:405-434

Greenaway W, Whatley FR (1990) Analysis of phenolics of bud exudate of Populus angustifolia by GC-MS. Phytochemistry 29:2551-2554

Greenaway W, Whatley FR (1991a) Analysis of phenolics of bud exudate of Populus ciliata by GC-MS. Phytochemistry 30:1887-1889

Greenaway W, Whatley FR (1991b) Analysis of phenolics of bud exudate of Populus sieboldii by GC-MS. Phytochemistry 30:3005-3008 
Greenaway W, May J, Whatley FR (1989) Flavonoid aglycones identified by gas chromatography-mass spectrometry in bud exudate of Populus balsamifera. J Chromatogr 472:393-400

Greenaway W, May J, Scaysbrook T, Whatley FR (1992) Compositions of bud and leaf exudates of some Populus species compared. Z Naturforsch 47c:329-334

Hanley SJ, Mallott MD, Karp A (2006) Alignment of a Salix linkage map to the Populus genomic sequence reveals macrosynteny between willow and poplar genomes. Tree Genet Genomes 3:35-48

Harrison JWH (1924) A preliminary account of the chromosomes and chromosome behavior in the Salicaceae. Ann Bot 38:361-378

Heil M (2008) Indirect defence via tritrophic interactions. New Phytol 178:41-61

Henderson I, Zhang R, Lu X, Johnson C, Meyers L, Green BC, Jacobsen PJ, May SE (2006) Dissecting Arabidopsis thaliana DICER function in small RNA processing, gene silencing and DNA methylation patterning. Nat Genet 38(6):721-725

Heslop-Harrison JS, Schwarzacher T (2011) Organisation of the plant genome in chromosomes. The Plant J 66(1):18-33

Hughes FMR, Barsoum N, Richards KS, Winfield M, Hayes A (2000) The response of male and female black poplar (Populus nigra L. subsp. betulifolia (Pursh) W. Wettst.) cuttings to different water table depths and sediment types: implications for flow management and river corridor biodiversity. Hydrol Processes 14:30753098

Hughes JF, Skaletsky H, Pyntikova T, Graves TA, van Daalen SKM, Minx PJ, Fulton RS, McGrath SD, Locke DP, Friedman C, Trask BJ, Mardis ER, Warren WC, Repping S, Rozen S, Wilson RK, David C (2010) Chimpanzee and human Y chromosomes are remarkably divergent in structure and gene content. Nature 463:536-539

Hyten DL, Song Q, Zhu Y, Choi IY, Nelson RL, Costa JM, Specht JE, Shoemaker RC, Cregan PB (2006) Impacts of genetic bottlenecks on soybean genome diversity. Proc Natl Acad Sci USA 103:16666-16671

Islam-Faridi MN, Nelson CD, DiFazio SP, Gunter LE, Tuskan GA (2009) Cytogenetic analysis of Populus trichocarpa - ribosomal DNA, telomere repeat sequence, and marker-selected BACs. Cytogenetic Genome Res 125(1):74-80

Jaillon O, Aury JM, Noel B, Policriti A, Clepet C, Casagrande A, Choisne N, Aubourg S, Vitulo N, Jubin C, Vezzi A, Legeai F, Hugueney P, Dasilva C, Horner D, Mica E, Jublot D, Poulain J, Bruyere C, Billault A, Segurens B, Gouyvenoux M, Ugarte E, Cattonaro F, Anthouard V, Vico V, Del Fabbro C, Alaux M, Di Gaspero G, Dumas V, Felice N, Paillard S, Juman I, Moroldo M, Scalabrin S, Canaguier A, Le Clainche I, Malacrida G, Durand E, Pesole G, Laucou V, Chatelet P, Merdinoglu D, Delledonne M, Pezzotti M, Lecharny A, Scarpelli C, Artiguenave F, Pe ME, Valle G, Morgante M, Caboche M, Adam-Blondon AF, Weissenbach J, Quetier F, Wincker P (2007) The grapevine genome sequence suggests ancestral hexaploidization in major angiosperm phyla. Nature 449:463-467

Jansson S, Douglas CJ (2007) Populus: a model system for plant biology. Ann Rev Plant Biol 58:435-458

Jones JDG, Dangl JL (2006) The plant immune system. Nature 444:323-329

Jones-Rhoades MWW, Bartel DPP, Bartel B (2006) MicroRNAs and their regulatory roles in plants. Ann Rev Plant Biol 57:19-53

Jorge V, Dowkiw A, Faivre-Rampant P, Bastien C (2005) Genetic architecture of qualitative and quantitative Melampsora laricipopulina leaf rust resistance in hybrid poplar: genetic mapping and QTL detection. New Phytol 167:113-127

Kaltz O, Shykoff JA (2001) Male and female Silene latifolia plants differ in per-contact risk of infection by a sexually transmitted disease. J Ecol 89:99-109
Karp A, Hanley SJ, Trybush SO, Macalpine W, Pei M, Shield I (2011) Genetic improvement of willow for bioenergy and biofuels. J Integr Plant Biol 53(2):151-165

Karrenberg S, Edwards PJ, Kollmann J (2002) The life history of Salicaceae living in the active zone of floodplains. Freshwater Biol 47:733-748

Klevebring D, Street NR, Fahlgren N, Kasschau KD, Carrington JC, Lundeberg J, Jansson S (2009) A genome-wide profiling of Populus small RNAs. BMC Genomics 10:620

Kohler A, Rinaldi C, Duplessis S, Baucher M, Geelen D, Duchaussoy F, Meyers BC, Boerjan W, Martin F (2008) Genome-wide identification of NBS resistance genes in Populus trichocarpa. Plant Molec Biol 66(6):619-636

Labbé J, Jorge V, Kohler A, Vion P, Marçais B, Bastien C, Tuskan G, Martin F, Le Tacon F (2011) Identification of quantitative trait loci affecting ectomycorrhizal symbiosis in an interspecific poplar F1 cross and differential expression of genes in ectomycorrhizas of the two parents: Populus deltoides and Populus trichocarpa. Tree Genet Genomes 7:617-627

Lescot M, Rombauts S, Zhang J, Aubourg S, Mathe C, Jansson S, Rouze P, Boerjan W (2004) Annotation of 95-kb Populus deltoides genomic sequence reveals a disease resistance gene cluster and novel class I and II transposable elements. Theor Appl Genet 109:10-22

Liesebach H, Naujoks G, Ewald D (2011) Successful hybridisation of normally incompatible hybrid aspen (Populus tremula $\times P$. tremuloides) and eastern cottonwood (P. deltoides). Sex Plant Reprod 24:189-198

Liu Z, Moore PH, Ma H, Ackerman CM, Ragiba M, Yu Q, Pearl HM, Kim MS, Charlton JW, Stiles JI, Zee FT, Paterson AH, Ming R (2004) A primitive $Y$ chromosome in papaya marks incipient sex chromosome evolution. Nature 427:348-352

Lokvam J, Braddock JF (1999) Anti-bacterial function in the sexually dimorphic pollinator rewards of Clusia grandiora (Clusiaceae). Oecologia 119:534-540

Mallory AC, Vaucheret H (2006) Functions of microRNAs and related small RNAs in plants. Nat Genet 38(Suppl):S31-S36

Markussen T, Pakull B, Fladung M (2007) Positioning of sexcorrelated markers for Populus in an AFLP- and SSR-marker based genetic map of Populus tremula $\times$ tremuloides. Silvae Genet $56: 180-184$

McDowell JM, Wolffenden BJ (2003) Plant disease resistance genes: recent insights and potential applications. Trends Biotech 21:178 183

McHale L, Tan X, Koehl P, Michelmore RW (2006) Plant NBS-LRR proteins: adaptable guards. Genome Biol 7:212-223

McLetchie DN, Tuskan GA, Dietrichson J (1994) Gender determination in Populus. J Agric Sci 18:57-66

Meurman O (1925) The chromosome behavior of some dioecious plants and their relatives with special reference to the sex chromosomes. Comm Biol Soc Sci Fennica 2:1-104

Meyers BC, Dickerman AW, Michelmore RW, Sivaramakrishnan S, Sobral BW, Young ND (1999) Plant disease resistance genes encode members of an ancient and diverse protein family within the nucleotide-binding superfamily. Plant J 20(3):317-332

Meyers BC, Kozik A, Griego A, Kuang HH, Michelmore RW (2003) Genome-wide analysis of NBS-LRR-encoding genes in Arabidopsis. Plant Cell 15:809-834

Ming R, Wang J, Moore PH, Paterson AH (2007) Sex chromosomes in flowering plants. Am J Bot 94:141-150

Muller HJ (1914) A gene for the fourth chromosome of Drosophila. J Exp Zool 17:325-336

Nagaraj M (1952) Floral morphology of Populus deltoides and $P$. tremuloides. Bot Gaz 114:222-243

Nakajima G (1937) Cytological studies in some dioecious plants. Cytologia Fuji Jub 282-292 
Navajas-Pérez R, de la Herrán R, López González G, Jamilena M, Lozano R, Ruiz Rejón C, Rui Rejón M, Garrido-Ramos MA (2005) The evolution of reproductive systems and sex-determining mechanisms within Rumex (Polygonaceae) inferred from nuclear and chloroplastidial sequence data. Mol Biol Evol 22:1929 1939

Nei M (1969) Linkage modification and sex difference in recombination. Genetics 63:681-699

Ohno S (1967) Sex chromosomes and sex-linked genes. SpringerVerlag, New York

Paape T, Igic B, Smith SD, Olmstead R, Bohs L, Kohn JR (2008) A 15-myr-old genetic bottleneck. Mol Biol Evol 25:655-663

Pakull B, Groppe K, Meyer M, Markussen T, Fladung M (2009) Genetic linkage mapping in aspen (Populus tremula L. and Populus tremuloides Michx.). Tree Genet Genomes 5:505-515

Pakull B, Groppe K, Mecucci F, Gaudet M, Sabatti M, Fladung M (2011) Genetic mapping of linkage group XIX and identification of sex-linked SSR markers in a Populus tremula $\times$ Populus tremuloides cross. Can J For Res 2:245-253

Palaisa K, Morgante M, Tingey S, Rafalski A (2004) Long-range patterns of diversity and linkage disequilibrium surrounding the maize Y1 gene are indicative of an asymmetric selective sweep. Proc Natl Acad Sci USA 101:9885-9890

Paolucci I, Gaudet M, Jorge V, Beritognolo I, Terzoli S, Kuzminsky E, Muleo R, Scarascia Mugnozza G, Sabatti M (2010) Genetic linkage maps of Populus alba L. and comparative mapping analysis of sex determination across Populus species. Tree Genet Genomes 6:863-875

Patterson N, Richter DJ, Gnerre S, Lander ES, Reich D (2006) Genetic evidence for complex speciation of humans and chimpanzees. Nature 441:1103-1108

Peto FH (1938) Cytology of poplar species and natural hybrids. Can J For Res 16:445-455

Purugganan MD, Fuller DQ (2009) The nature of selection during plant domestication. Nature 457:483-489

Pusey P, Curry E (2004) Temperature and pomaceous flower age related to colonization by Erwinia amylovora and antagonists. Phytopathology 94:901-911

Richy E, Kurth J, Leister D (2002) Mode of amplification and reorganization of resistance gens during recent Arabidopsis thaliana evolution. Mol Biol Evol 19:76-84

Rottenberg A, Nevo E, Zohary D (2000) Genetic variability in sexually dimorphic and monomorphic populations of Populus euphratica (Salicaceae). Can J For Res 30:482-486

Rowland DL, Garner R, Jespersen M (2002) A rare occurrence of seed formation on male branches of the dioecious tree, Populus deltoides. Am Midl Nat 147:185-187

Salse J, Abrouk M, Bolot S, Guilhot N, Courcelle E, Faraut T, Waugh R, Close TJ, Messing J, Feuillet C (2009) Reconstruction of monocotelydoneous proto-chromosomes reveals faster evolution in plants than in animals. Proc Natl Acad Sci USA 106:14908-14913

Sánchez-Rodríguez C, Estévez JM, Llorente F, Hernández-Blanco C, Jordá L, Pagán I, Berrocal M, Marco Y, Somerville S, Molina A (2009) The ERECTA receptor-like kinase regulates cell wallmediated resistance to pathogens in Arabidopsis thaliana. Mol Plant-Microbe Inter 22(8):953-963

Shuklaa LI, Chinnusamy V, Sunkar R (2008) The role of microRNAs and other endogenous small RNAs in plant stress responses. Biophysica Acta 1779(11):743-748

Shykoff JA, Bucheli E, Kaltz O (1997) Anther smut disease in Dianthus silvester (Caryophyllaceae): natural selection on floral traits. Evolution 51:383-392

Slavov GT, Leonardi S, Adams WT, Strauss SH, DiFazio SP (2010) Population substructure in continuous and fragmented stands of Populus trichocarpa. Heredity 105:348-357
Smith EC (1943) A study of cytology and speciation in the genus Populus L. J Arnold Arboretum 24:275-305

Smith BW (1963) The mechanism of sex determination in Rumex hastatulus. Genetics 48:1265-1288

Stettler R (1971) Variation in sex expression of black cottonwood and related hybrids. Silvae Genet 20:42-46

Strauss SY (1997) Floral characters link herbivores, pollinators and plant fitness. Ecology 78(6):1640-1645

Stretch AW, Ehlenfeldt MK (2000) Resistance to the fruit infection phase of mummy berry disease in highbush blueberry cultivars. HortSci 35:1271-1273

Tagu D, Bastien C, Faivre-Rampant P, Garbaye J, Vion P, Le Tacon F, Martin F (2005) Genetic analysis of phenotypic variation for ectomycorrhizal formation in an interspecific $F_{1}$ poplar full-sib family. Mycorrhiza 15:87-91

Tavares LS, Santos MO, Viccini LF, Moreira JS, Miller RN, Franco OL (2008) Biotechnological potential of antimicrobial peptides from flowers. Peptides 29(10):1842-1851

Thadeo M, Cassino MF, Vitarelli NC, Azevedo AA, Araujo JM, Valente VMM, Meira RMSA (2008) Anatomical and histochemical characterization of extrafloral nectaries of Prockia crucis (Salicaceae). Am J Bot 95(12):1515-1522

Theis N, Kesler K, Adler LS (2009) Leaf herbivory increases floral fragrance in male but not female Cucurbita pepo subsp. texana (Cucurbitaceae) flowers. Am J Bot 96(5):897-903

Tsai CJ, Harding SA, Tschaplinski TJ, Lindroth RL, Yuan Y (2006) Genome-wide analysis of the structural genes regulating defense phenylpropanoid metabolism in Populus. New Phytol 172:47-62

Tuskan GA, DiFazio S, Jansson S, Bohlmann J, Grigoriev I, Hellsten U, Putnam N, Ralph S, Rombauts S, Salamov A, Schein J, Sterck L, Aerts A, Bhalerao RR, Bhalerao RP, Blaudez D, Boerjan W, Brun A, Brunner A, Busov V, Campbell M, Carlson J, Chalot M, Chapman J, Chen GL, Cooper D, Coutinho PM, Couturier J, Covert S, Cronk Q, Cunningham R, Davis J, Degroeve S, Dejardin A, Depamphilis C, Detter J, Dirks B, Dubchak I, Duplessis S, Ehlting J, Ellis B, Gendler K, Goodstein D, Gribskov M, Grimwood J, Groover A, Gunter L, Hamberger B, Heinze B, Helariutta Y, Henrissat B, Holligan D, Holt R, Huang W, IslamFaridi N, Jones S, Jones-Rhoades M, Jorgensen R, Joshi C, Kangasjarvi J, Karlsson J, Kelleher C, Kirkpatrick R, Kirst M, Kohler A, Kalluri U, Larimer F, Leebens-Mack J, Leple JC, Locascio P, Lou Y, Lucas S, Martin F, Montanini B, Napoli C, Nelson DR, Nelson C, Nieminen K, Nilsson O, Pereda V, Peter G, Philippe R, Pilate G, Poliakov A, Razumovskaya J, Richardson P, Rinaldi C, Ritland K, Rouze P, Ryaboy D, Schmutz J, Schrader J, Segerman B, Shin H, Siddiqui A, Sterky F, Terry A, Tsai CJ, Uberbacher E, Unneberg P, Vahala J, Wall K, Wessler S, Yang G, Yin T, Douglas C, Marra M, Sandberg G, Van de Peer Y, Rokhsar D (2006) The genome of black cottonwood, Populus trichocarpa (Torr. \& Gray). Science 313(5793):1596-1604

Vamosi JC, Otto SP (2002) When looks can kill: the evolution of sexually dimorphic floral display and the extinction of dioecious plants. Proc Roy Soc Lond B 269:1187-1194

van Buijtenen JP, Einspahr DW (1959) Note on the presence of sex chromosomes in Populus tremuloides. Bot Gaz 121:60-61

Van Dillewijn C (1940) Zytologische studien in der gattung Populus. Genetica 22:131-182

Yang X, Kalluri UC, Jawdy S, Gunter LE, Yin T, Tschaplinski TJ, Weston DJ, Ranjan P, Tuskan GA (2008) The F-box gene family is expanded in herbaceous annual plants relative to woody perennial plants. Plant Physiol 148:1189-1200

Yin TM, DiFazio SP, Gunter LE, Riemenschneider D, Tuskan GA (2004a) Large-scale heterospecific segregation distortion in Populus revealed by a dense genetic map. Theor Appl Genet 109:451-463 
Yin TM, DiFazio SP, Gunter LE, Jawdy SS, Boerjan W, Tuskan GA (2004b) Genetic and physical mapping of Melampsora rust resistance genes in Populus and characterization of linkage disequilibrium and flanking genomic sequence. New Phytol 164:95-105

Yin T, DiFazio SP, Gunter LE, Zhang X, Sewell MM, Woolbright SA, Allan GJ, Kelleher CT, Douglas CJ, Wang M, Tuskan GA (2008)
Genome structure and emerging evidence of an incipient sex chromosome in Populus. Genome Res 18:422-430

Zhang J, Steenackers M, Storme V et al (2001) Fine mapping and identification of nucleotide binding site/leucine-rich repeat sequences at the MER locus in Populus deltoides 'S9-2'. Phytopathology 91:1069-1073 